\title{
Study on Stress Among Male Resident Medical Students: A Cause of Concern
}

\author{
Sunil Kumar ${ }^{2}$, Neelam Kotwal ${ }^{1}$, Monika Malhotra ${ }^{2}$, Saurabh Sadotra ${ }^{2}$, Pankaj Kumar ${ }^{3}$ and Mohammad Sarwar \\ Mir $^{3 *}$
}

${ }^{1}$ Former Medical Officer at Shri Mata Vaishno Devi Shrine Board, India

${ }^{2}$ IMO Grade 1 ESIC Hospital, India

${ }^{3}$ SKIMS Soura, India

*Corresponding author: Mohammad Sarwar Mir, SKIMS Soura, India

\begin{abstract}
Introduction: Stress is an inevitable part of medical education and is especially common in Resident medical scholars.

Objective: To study causes of stress among Resident medical students

Materials and Methods: A cross-sectional study was carried in May 2015. A 140 male resident scholars were included and gave consent. A predesigned, semi structured questionnaire was used.

Result: Analysis shows that $71.4 \%$ of the respondents experienced stress. Being way from the family, large syllabus, and lack of time to revise were the major causes of stress among the students.

Conclusion: A good proportion of resident medical students were found to be stressed, with academic stressors being the major cause of stress among the subjects.
\end{abstract}

Keywords: Stress; Medical Students; Residents; Hostels

\section{Introduction}

Stress is defined as "a highly subjective phenomenon and it is a nonspecific response of body to any demand for change [1]." A stressor is defined as the personal or environmental event that causes stress. Stress is an inevitable part of medical education and can affect students at any stage of their study. Sleepless nights, depression [2], suicidal ideation [3], addictions to dependenceproducing drugs for coping up with stress, and poor performance at examinations in spite of doing hard work are some of the ill effects of stress. Resident scholars are more prone to stress as they are away from family which adds to their woes. Thus an attempt was made to study the stress among the resident medical scholars.

\section{Objective}

To Identify the causes leading to increased stress among Resident medical students.

\section{Materials and Methods}

A cross sectional survey was carried out in a boys hostel of a medical college in Jammu and Kashmir. A total 100 hostel inmates participated in the process. A predesigned questionnaire was used to study the leading causes of stress. The first part comprised demographic information of students such as age, sex, and residence. The second part of the questionnaire included questions about the causative factors of stress. The third part consisted of questions related to activities done to relieve stress.

Statistical analysis was done using SPSS2.0and Excel.

\section{Result}

A total of 140 resident medical scholars participated in the study. A total of $100(71.44 \%)$ respondents revealed some ill effects of stress (Figure 1). 


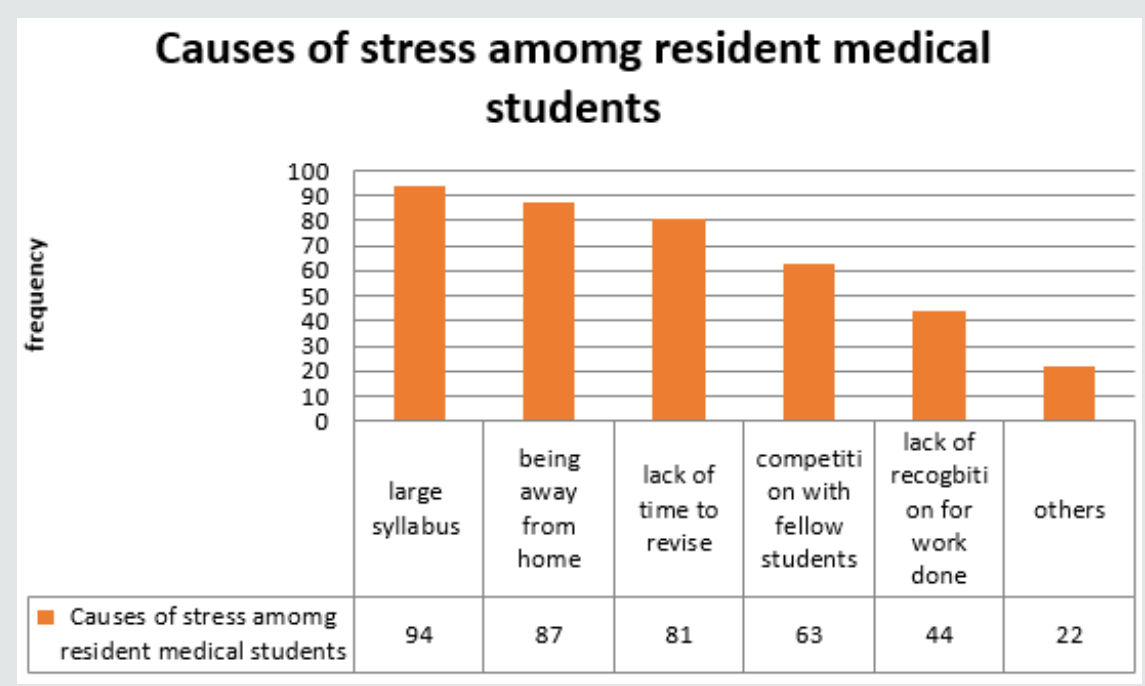

Figure 1: Causes of Stress.

\section{Discussion}

This study confirmed the general impression that stress is common among medical students with a prevalence of $71.4 \%$ among our study group. The findings of this study are by and large similar to other studies $[1,4,5,6]$. The major cause of stress in the study is found out to be academic related which included large syllabus to be learnt, being away from family, lack of time to revise the subject, difficulty in understanding the subject, poor performance at the examination, and lack of recognition of work done by students. Other nonsignificant academic factors include poor relationship with professors, poor participation in class discussion, and lack of interest in learning. Poor performance in the examinations was accreted mainly owing to lack of time for revision and large content to be learnt. Our study also included the type and measure of stress-coping skills adopted by the students (Figure $2)$,playing games and sports (30\%) was the common strategy employed by the students to relive stress followed by use of social media like Facebook (24\%). About $21 \%$ of them were not involved in any activity to cope up with stress, $12 \%$ involved in listening to music, and $8 \%$ used sleeping to cope stress $[7,8]$.

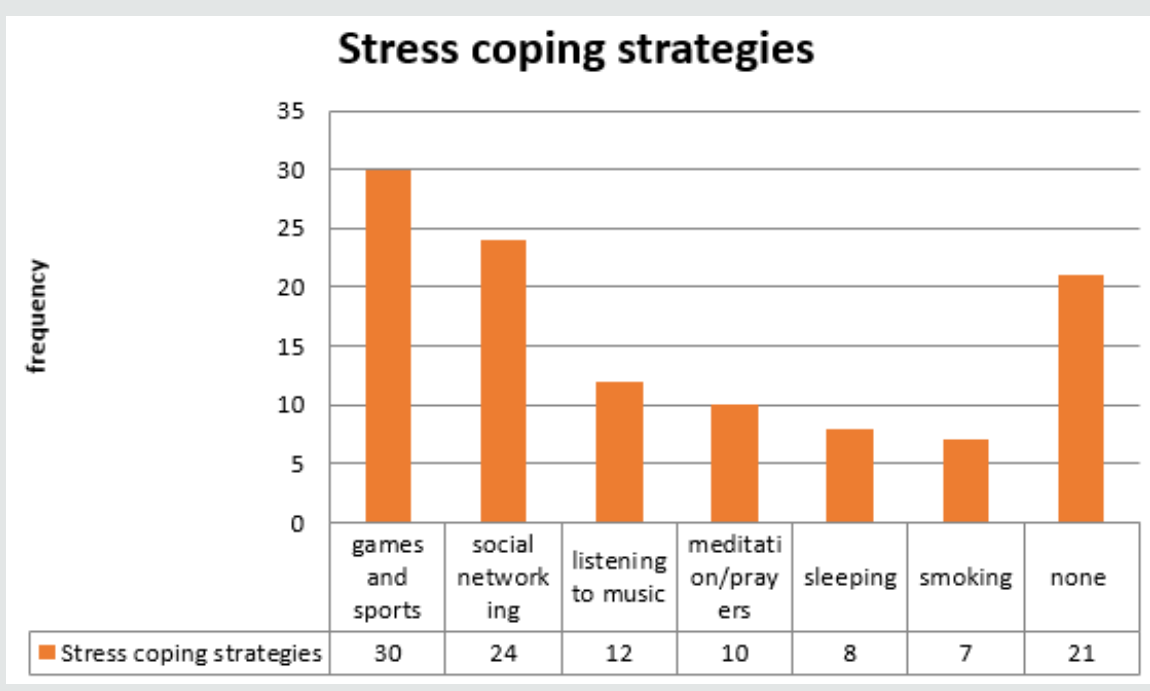

Figure 2: Stress coping strategies.

\section{Conclusion}

The study revealed that academic problems were greater sources of stress and being away from family was also a major cause of stress. Student distress may influence professional development and adversely impact academic performance contributing to academic dishonesty and substance abuse. Addressing these issues using professional help would go a long way in ameliorating their stress levels and in making their learning a pleasant affair.

\section{References}

1. Sreedevi A, Rao GV, Bharath P, Reddy K, Parigala R, et al. (2016) Study on stress among first-year medical students of Kurnool Medical College, Kurnool. Int J Med Sci Public Health 5(5): 852-855.

2. Sidik SM, Rampal L, Kaneson N (2003) Prevalence of emotional disorders among medical students in a Malaysian university. Asia Pac Family Med 2(4): 213-217. 
3. Rajiv Radhakrishnan, Chittaranjan Andrade (2012) Suicide: An Indian perspective. Indian J Psychiatry 54(4): 304-319.

4. Madhyastha S, Latha KS, Kamath A (2014) Stress and coping among final year medical students. AP J Psychol Med 15(2): 74-80.

5. Stewart SM, Betson C, Marshall I, Wong CM, Lee PW, et al. (1995) Stress and vulnerability in medical students. Med Educ 29(2): 119-127.

6. Birks Y, McKendree J, Watt I (2009) Emotional intelligence and perceived stress in healthcare students: a multi-institutional, multi-professional survey. BMC Med Educ 9: 61.

7. Firth J (1986) Levels and sources of stress in medical students. Br Med J (Clin Res Ed) 292(6529): 1177-1180.

8. Kaufman DM, Day V, Mensink D (1996) Stressors in first-year medical school: comparison of a conventional and problem-based curriculum. Teach Learn Med 8(4): 188-194.

\begin{tabular}{|c|c|}
\hline & $\begin{array}{c}\text { Scholarly Journal of Psychology } \\
\text { and Behavioral Sciences }\end{array}$ \\
\hline sid.s & $\begin{array}{l}\text { Assets of Publishing with us } \\
\text { - Global archiving of articles } \\
\text { - Immediate, unrestricted online access } \\
\text { - } \quad \text { Rigorous Peer Review Process }\end{array}$ \\
\hline $\begin{array}{c}\text { Scholarly Journal of } \\
\text { Psychology \& Behavioral sciences }\end{array}$ & $\begin{array}{l}\text { - Authors Retain Copyrights } \\
\text { - Unique DOI for all articles }\end{array}$ \\
\hline
\end{tabular}

